\title{
LAND COVER CHANGE DYNAMICS AND THEIR IMPACTS ON THERMAL ENVIRONMENT OF DADRI BLOCK, GAUTAM BUDH NAGAR, INDIA
}

\author{
Sushma SHASTRI ${ }^{1}$, PrAfUll SingH* ${ }^{1}$, PRADIPIKA VERMA $^{1}$, \\ PRAVEEN KUMAR RAI ${ }^{1}$ AND A. P.SINGH ${ }^{2}$
}

\author{
${ }^{1}$ Amity Institute of Geoinformatics and Remote Sensing, Amity University, \\ Sector-125, Noida, India \\ ${ }^{2}$ Census Commissioner of India (Map Division), New Delhi, India \\ *Corresponding author e-mail: pks.jiwaji@gmail.com
}

Received: $10^{\text {th }}$ April 2020, Accepted: $23^{\text {th }}$ May 2020

\begin{abstract}
Land use / land cover (LULC) has been considered as one of the important bio-physical parameters and have significant affect on local environmental change, particularly increasing anthropogenic temperature. Remote sensing images from Landsat series satellites are a major information source for LULC change analysis. In the present investigation, long term changes in LULC and its negative impact on land surface temperature (LST) were analyzed using multi-temporal Landsat satellite images between 2000 to 2016. firstly LULC of the study area has been classified and temporal changes in land use classes were quantify, and observed that in most of the land use classes such as vegetation $(-1.28 \%)$, water bodies $(-1.65 \%)$, agriculture $(-3.52)$ and open land $(-2.43 \%)$ have shown negative change, however large scale positive changes in built-up area $(+8.87 \%)$ has been observed during the analysis, which is mainly due to continuous urbanization and growth of population in the area. The classified thermal images from the same period also show mean temperature of the area has increased by $1.60{ }^{\circ} \mathrm{C}$ since last 16 years. The observation from the present study reveals that due to the large-scale land use change practices in urban and peri-urban area witnessed for the rising temperature due to loss natural vegetation and other natural resources.
\end{abstract}

Keywords: Satellite images, Land use/ land cover, LST, Remote Sensing, Landsat data.

\section{INTRODUCTION}

Rapid and unplanned urbanization is being seen worldwide especially in developing countries like India. More and more people are opting to stay in urban areas thus fueling urban growth. The rapid urbanization is posing a threat to the environmental sustainability and can be judged by observing the correlation between rise in temperatures due to global warming, reduction of vegetation cover and urban growth in cities (Li et. al., 2010).

The thermal comfort of city inhabitants is directly (Harlan et. al., 2006, Lafortezza et. al., 2009) and indirectly (Stafoggia et.al., 2008) affected by UHIs. Urban Heat Island (UHIs) not only effect water use and biodiversity change but also contribute to human discomfort by increasing the source of death and disease (Basara et.al., 2010). Change in the land use and land cover are the reason of intense development and change in lifestyle due for better 
Shastri S., Singh P., Verma P., Rai P.K, Singh A.P.: Land cover change dynamics and their impacts on thermal environment of Dadri Block, Gautam Budh Nagar, India

livelihood which plays important role in global and local change and it affects the earth's natural resources and environment of the surroundings (Alipour et.al., 2003; Amiri et.al., 2009; Mishra \& Rai, 2016; Singh \& Rai, 2017; Mishra et.al., 2019). The transformation of the land from natural landscape to manmade structures such as built -up area includes industrial, residential, roads networks etc. are affecting the local environment of the region such as it induces the land surface temperature, climate change, and degradation in many natural resources. By the end of this century, the average surface temperature of the earth will rise about $1.1^{\circ} \mathrm{C}-6.4^{\circ} \mathrm{C}$ according to the IPCC report (Saud et al., 2017).

Remotely sensed thermal infrared (TIR) data have been widely used to retrieve land surface temperature (LST) (Quattrochi \& Luvall, 1999; Weng et al., 2004). The recent development of high-resolution satellite images means that detailed analyses could be expected. To estimate the thermal condition of land surface by satellite image, it is necessary to find the relationship between the surface temperature, surrounding topography and land cover /use (Weng, 2009).

Hence, it is necessary to monitor Land use and Land surface temperature regularly as it is responsible for the irreversible impact on the ecology and environment of the region. Land use / Land cover mapping and Land surface temperature extraction has been done effectively by using multi- temporal satellite data (Li et.al., 2012; Singh et al., 2012 ; Chaudhuri et al., 2018; Verma et al., 2019). Land use / land cover is an important factor that affects the land surface temperature directly. The reflectances of the land use class are behaved different therefore land surface temperature also affected and creating the difference in their values. Therefore, the relationship between land surface temperature and land use and land cover should be necessary to investigate the analysis of environmental parameters. The advantages of using remotely sensed data are the availability of high resolution, consistent and repetitive coverage and capability of measurements of earth surface conditions (Owen et al., 1998). Earth observation datasets obtained through satellites give a unique insight into the change in land use and cover by comparison of satellite imagery taken over a period.

With the advent of remote sensing technology, it is possible to study the impact of land use/land cover change on urban thermal environments. Images from the Landsat series are often used to detect spatio-temporal variations of urban impervious surface, vegetation, and LST (Woodcock \& Strahler 1987; Zhang et.al., 2009, Kikon et al., 2016; Singh et al., 2017). Ability to get high resolution imagery continuously of the area of interest through Remote Sensing gives constant updates and ability to calculate and predict change in environmental sustainability of a city. The present study focused on the multi temporal satellite images to monitor the changes in land use/land cover and its impact and relation to land surface temperature of the Dadri block of Gautam Budh Nagar, Uttar Pradesh, India.

\section{STUDY AREA}

Dadri is an important semi-urban block in Gautam Buddha Nagar District of Uttar Pradesh State, India. Dadri is located between the geographic latitudes $28^{\circ} 25^{\prime}-28^{\circ} 40^{\prime} \mathrm{N}$ and longitudes $77^{\circ} 30^{\prime}-78^{\circ} 40^{\prime} \mathrm{E}$ (Fig.1) and covering an area about $203 \mathrm{Sq}$. Km. It has an average elevation of 216 meters ( $709 \mathrm{ft}$ ) and most of the block has flat topography. This plain is slightly lower in the central part than its eastern and western sides but the general slope is towards south. Geologically, the region belongs to quaternary alluvium deposits with variting grade of gravel and sand of recent origin. In summer highest day temperature is range between $23^{\circ} \mathrm{C}$ to $45^{\circ} \mathrm{C}$ with average temperatures of January is $15^{\circ} \mathrm{C}$, February is $17^{\circ} \mathrm{C}$, March is $23^{\circ} \mathrm{C}$, April is $29^{\circ} \mathrm{C}$, May is $34^{\circ} \mathrm{C}$. Being a part of NCR region, the 
temperature is similar to that of Delhi. In the summer, the climate is quite hot and likewise the winter is also quite cold. The rains are heavy and widespread. The monsoon starts from the last week of June and continues till the end of September. The span of summer season is from March to June and winter season from October to February. The cold waves from the Himalayan region make the winters chilly and harsh. A temperature goes down to as low as 3 to $4^{\circ} \mathrm{C}$ in the peak time of winters. The town also faces a problem of fog and smog. More than $90 \%$ of the annual rainfall occurs in monsoon season. On an average, there are approximately 40 rainy registered in the region. The whole of district forms alluvial deposits the exact thickness of which is considerable but not known. The chief soil of the region is rich loam. Dadri block of Gautam Buddha Nagar district has total population of 1,110,093 as per the Census 2011.

Fig. 1: Location of the study area
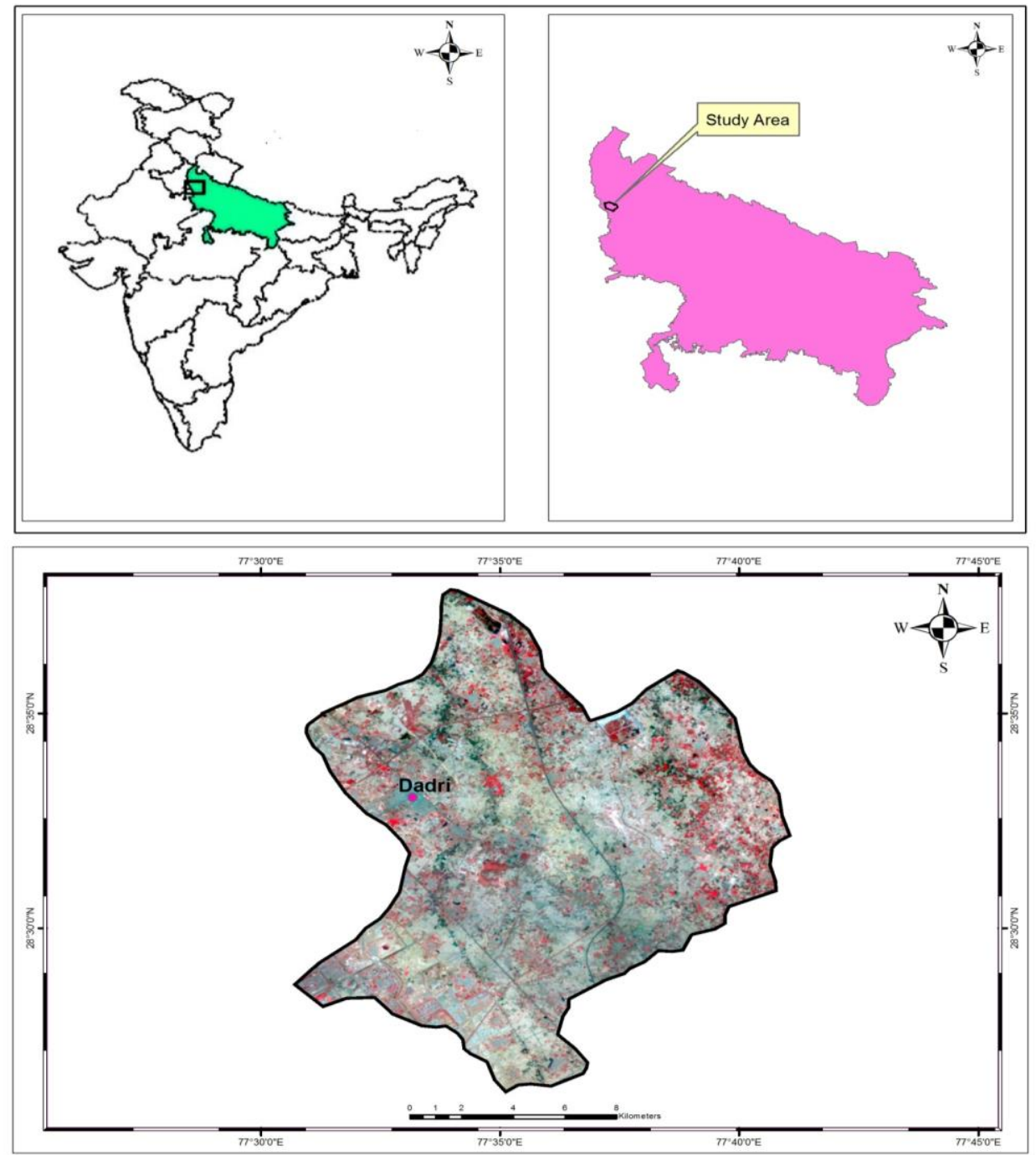
Shastri S., Singh P., Verma P., Rai P.K, Singh A.P.: Land cover change dynamics and their impacts on thermal environment of Dadri Block, Gautam Budh Nagar, India

\section{DATA USED AND METHODOLOGY}

Landsat-8 is the latest among the Landsat series of NASA \& USGS. The data of Landsat 8 is available in Earth Explorer website at free of cost. In this study, Landsat-8 OLI Images of pertaining to the study area was used to calculate NDVI and the estimation of LST. Single window algorithm method has employed to find out LST in the study area. Vegetation proportion calculation, emissivity calculation, LST calculation etc. were executed in ArcGIS 10 software platform.

Land use/land cover maps and land surface temperature distribution of the study area are the two main subsections in which the methodology and data sets used (Table $1 \&$ Figure 2). The standard methodology of satellite image classification and generation of land surface temperature (LST) from satellite data is given the Fig. 2. The surface temperature was mathematically derived and computed in tabular and map forms which identified the land uses/land covers information from the each of the steps carried out.

Table 1: Data used and its sources

\begin{tabular}{|l|l|l|l|}
\hline \multicolumn{1}{|c|}{ Satellite Data } & Date Acquired & Path \& Row & Source \\
\hline $\begin{array}{l}\text { Landsat-7 Enhanced Thematic } \\
\text { Mapper Plus (ETM+) }\end{array}$ & $08-10-2000$ & 146,40 & https://earthexplorer.usgs.gov \\
\cline { 1 - 1 } $\begin{array}{l}\text { Landsat-8 } 8 \text { Operational Land Imager (OLI) } \\
\text { and Thermal Infra-Red Scanner } \\
\text { (TIRS) }\end{array}$ & $09-10-2016$ & 146,40 & \\
\hline
\end{tabular}

Fig. 2: Methodology of calculation of LULC and LST

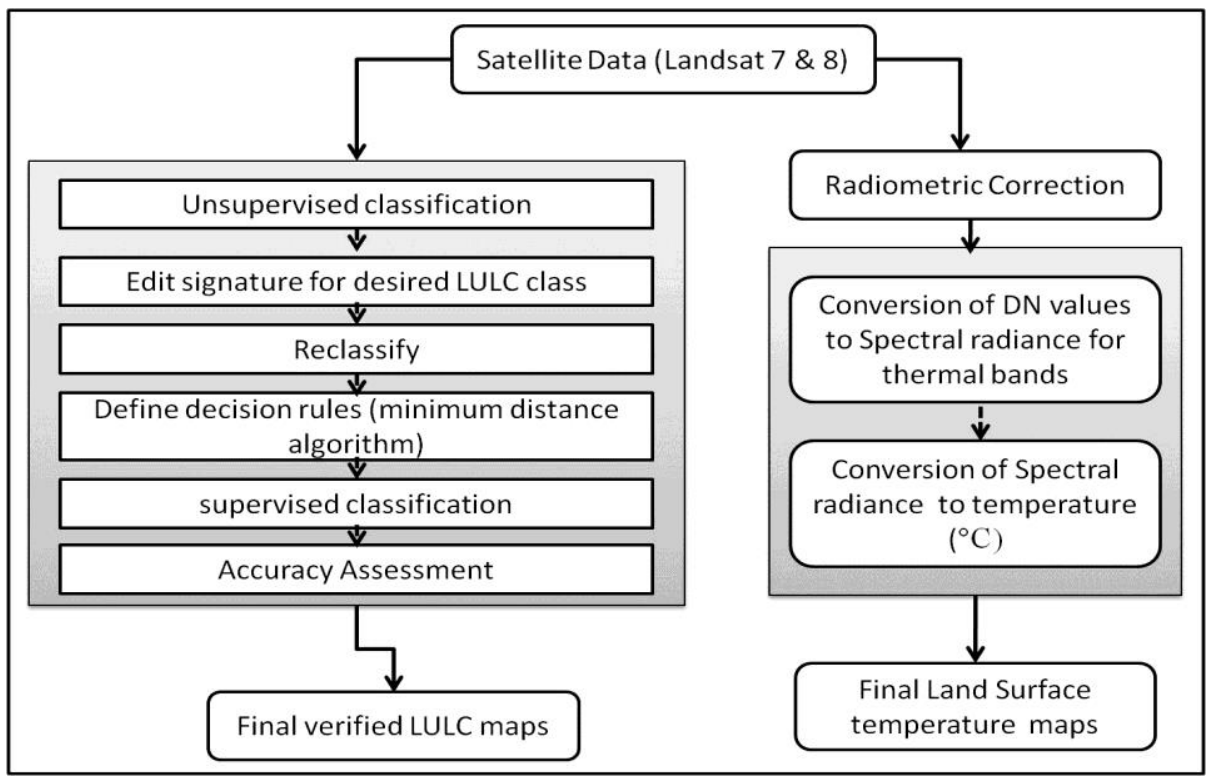




\section{Land Use/Land Cover (LULC) Classification}

Land use/land cover classification has been done by using multi-temporal satellite images (Landsat 7\& 8) of year 2000 and 2016. Mapping of LULC has done by using hybrid supervised classification technique along with GPS survey of Dadri block of Gautam Budh Nagar, Uttar Pradesh, India (Figure 2). The major categories of LULC are Vegetation, Agricultural land, Open land, Built-up area and water bodies based on the spectral values. The Classified maps were verified by performing the accuracy assessment that includes producer's and User's accuracy.

\section{Land Surface Temperature from Thermal Bands}

- The land surface temperature (LST) is a good indicator of the energy balance at the Earth's surface because it is one of the key parameters in the physics of land-surface processes on regional and global scales. The land surface temperature (LST) distribution mapping has been done by using Landsat satellite imageries of year 2000 and 2016. LST in 2016 has been derived from both the bands $10 \& 11$ whereas other bands are used for the land classification. Basically, there are five steps to be followed for the extraction of the land surface temperature from the Landsat thermal bands which are given below

- Conversion of digital number (DN) to Spectral radiance

- Conversion of spectral radiance to atmosphere brightness temperature

- Generate Normalized Differential Vegetation Index (NDVI)

- Calculate Land surface emissivity (LSE)

- Calculation for Land surface temperature from Kelvin to degree Celsius

\section{i. $\quad$ Conversion of digital number to Spectral radiance $\left(L_{\lambda}\right)$}

The equation given below indicates the spectral radiance that was calculated with digital number (Nichol \& To, 2012):

$\mathrm{L}_{\lambda}=\mathrm{R}_{\mathrm{ML}}$ x Qcal $+\mathrm{R}_{\mathrm{A}}-\mathrm{O}_{\mathrm{i}}$

Where, $\mathrm{L}_{\lambda}=$ Spectral radiance $\left(\right.$ Watts $\left(\mathrm{m}^{2} \mathrm{x}\right.$ sr $\left.\mathrm{x} \mu \mathrm{m}\right)$ ), $\mathrm{R}_{\mathrm{ML}}=$ Band-specific multiplicative rescaling factor, $\mathrm{R}_{\mathrm{A}}=$ Band-specific additive rescaling factor, $\mathrm{Qcal}=$ Digital number of a given pixel

\section{ii. Conversion of spectral radiance to atmosphere brightness temperature:}

In this step top of the atmosphere brightness temperature was calculated by using spectral radiance which was derived from

$\mathrm{BT}=\mathrm{K}_{2} / \ln \left(\mathrm{K}_{1} / \mathrm{L}_{\lambda}+1\right)-272.15$

Where,

$\mathrm{BT}=$ Top of the atmosphere brightness temperature,

$\mathrm{L}_{\lambda}=$ Spectral radiance $\left(\right.$ Watts $/\left(\mathrm{m}^{2} \mathrm{x}\right.$ sr $\left.\left.\mathrm{x} \mu \mathrm{m}\right)\right), \mathrm{K}_{1} \& \mathrm{~K}_{2}=$ are two calibration constants prior to launching (For Landsat 7 the $\mathrm{K}_{1}$ and $\mathrm{K}_{2}$ values are 607.76 \& 1260.56 respectively whereas for Landsat 8, the constant values of $\mathrm{K}_{1}$ and $\mathrm{K}_{2}$ in band 10 are 774.88 \& 1321.08 respectively and for band 11 values are $480.88 \& 1201.14$ respectively).

\section{iii. $\quad$ Generate Normalized Differential Vegetation Index (NDVI)}

It is standardized vegetation index which is calculated by using near infra-red and red bands. The formula used for the calculation of the NDVI is given below: 
Shastri S., Singh P., Verma P., Rai P.K, Singh A.P.: Land cover change dynamics and their impacts on thermal environment of Dadri Block, Gautam Budh Nagar, India

$\mathrm{NDVI}=(\mathrm{NIR}-\mathrm{RED}) /(\mathrm{NIR}+\mathrm{RED})$

Where, NIR $=$ DN values Near Infra Red Bands \& RED $=$ DN values of Red bands

\section{iv. $\quad$ Calculate Land surface emissivity (LSE)}

Land surface emissivity (LSE) show the average emissivity of an element of the land surface which is calculated from the normalized Differential vegetation index (NDVI). Formula given below used for calculation of LSE:

Land Surface Emissivity (LSE) $=0.004 \times$ PV +0.986

Where, $\mathrm{PV}=$ Proportion of Vegetation which is derived from the given formula:

$\left.\mathrm{PV}=\left[\left(\mathrm{NDVI}-\mathrm{NDVI}_{\min }\right) / \mathrm{NDVI}_{\max }+\mathrm{NDVI}_{\min }\right)\right]^{2}$

Where, NDVI= Normalized Differential Vegetation Index value,

$\mathrm{NDVI}_{\text {min }} \& \mathrm{NDVI}_{\max }=$ Minimum and Maximum values of the NDVI

\section{v. Calculation for Land surface temperature from Kelvin to degree Celsius}

Land Surface Temperature (LST) is the radiative temperature that is calculated from the formula given below:

$\mathrm{LST}=(\mathrm{BT} / 1)+\mathrm{W} \times(\mathrm{BT} / 14380) \times \ln (\mathrm{LSE})$

Where, $\mathrm{BT}=$ Top of the atmosphere brightness temperature $\left({ }^{\circ} \mathrm{C}\right), \mathrm{W}=$ wavelength of emitted radiance, and LSE = Land surface emissivity

\section{RESULT}

\section{Spatial changes in Land Use/Land Cover}

Spatial distribution of the land use/ land cover (LULC) and its changes from 2000 and 2016 have been classified and mapped (Figure 3 ). There are various method used in carrying out supervised land cover such as the box classifier (parallelepiped), the Minimum Distance to Mean (MDM) and the Maximum likelihood method. However, the maximum likelihood method was chosen because a weighting which helps to minimise errors that may arise due to misclassification can be applied during the classification process.

The major LULC classes are built-up area, vegetation cover, agricultural land / Fallow land, open area and water bodies. The spatial distributions of each class of LULC in last 16 years (Table 2) and classified maps indicate that the major positive changes are in built-up area of $9 \%$. The area of the built-up is increased from $7 \mathrm{~km}^{2}$ to $25 \mathrm{~km}^{2}$ from 2000 to 2016 total change in area of $18 \mathrm{~km}^{2}$. Whereas remaining classes show negative change, major negative changes are observed in agricultural and open land classes which are $3 \%$ and $2 \%$ respectively from 2000 to 2016 . The total change in agriculture land in 2000 was $160 \mathrm{~km}^{2}$, whereas it decreased to $153 \mathrm{~km}^{2}$ in 2016 . The area of the open land also decreased from $12 \mathrm{~km}^{2}$ to $7 \mathrm{~km}^{2}$ with $4.9 \mathrm{~km}^{2}$ area from 2000 to 2016 . Another majorly affected class was vegetation cover which show change in area of about $3 \mathrm{~km}^{2}$. 
Fig. 3: Land Use/Land Cover Change of the Study area 2000 \& 2016
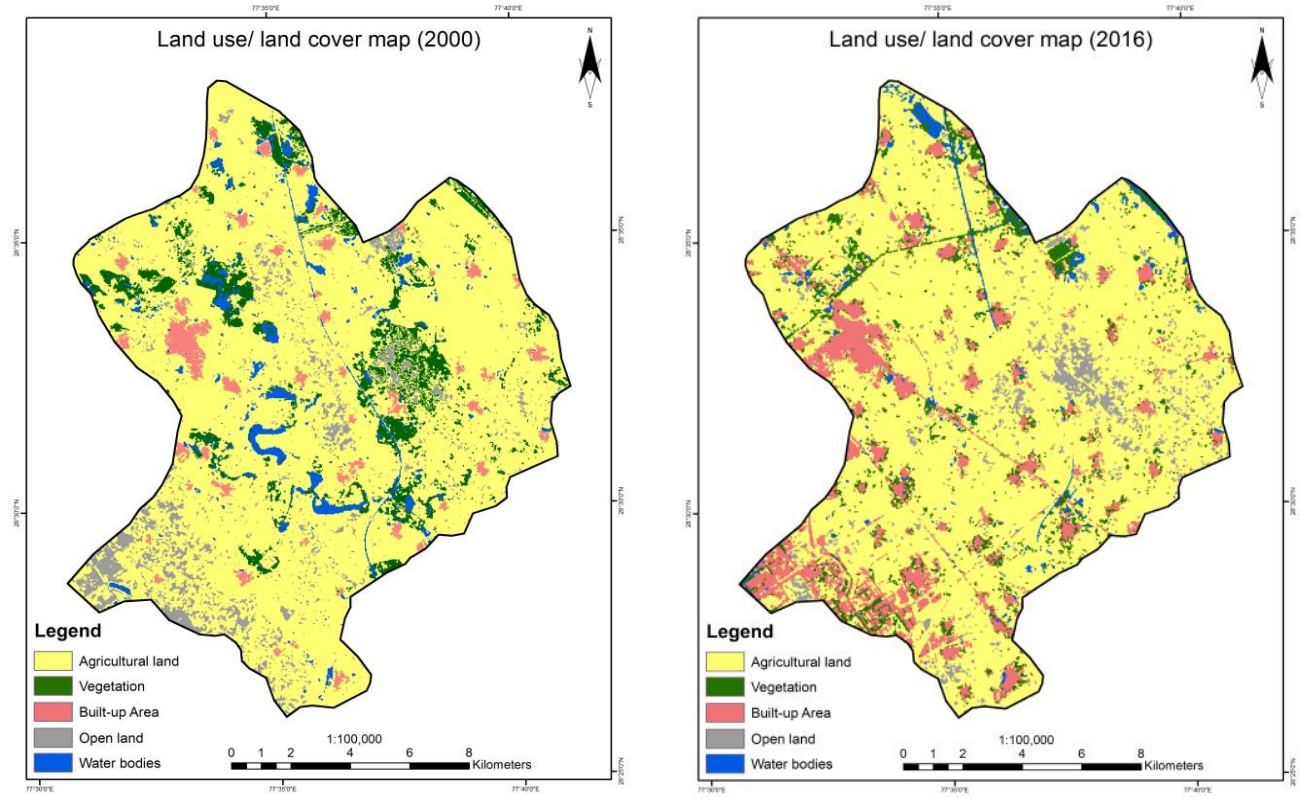

Table 2: Spatial Changes in Land Use / Land Cover from 2000 \& 2016

\begin{tabular}{|l|c|c|c|c|c|c|}
\hline \multirow{2}{*}{ LULC classes } & \multicolumn{2}{|c|}{ 2000 } & \multicolumn{2}{c|}{2016} & \multicolumn{2}{c|}{ Change } \\
\cline { 2 - 7 } & Area (sq.km) & Area (\%) & $\begin{array}{l}\text { Area } \\
\text { (sq.km) }\end{array}$ & Area (\%) & $\begin{array}{l}\text { Area } \\
\text { (sq.km) }\end{array}$ & Area (\%) \\
\hline Vegetation & 16.41 & 8.08 & 13.85 & 6.80 & -2.56 & -1.28 \\
\hline Water bodies & 7.53 & 3.71 & 4.20 & 2.06 & -3.33 & -1.65 \\
\hline Agriculture land & 159.99 & 78.71 & 153.29 & 75.19 & -6.7 & -3.52 \\
\hline Built-up & 6.88 & 3.39 & 24.99 & 12.26 & 18.11 & +8.87 \\
\hline Open land & 12.45 & 6.12 & 7.52 & 3.69 & -4.93 & -2.43 \\
\hline Total Area & 203.27 & 100 & 203.86 & 100 & & \\
\hline
\end{tabular}

\section{Land Surface Temperature (LST)}

The land surface distribution of the study area of 2000 map shows that, the highest temperature of $35^{\circ} \mathrm{C}$ lies near the built-up/ settlement area and the lowest $25^{\circ} \mathrm{C}$ in the class of vegetation cover, hence it indicates the difference of about $10^{\circ} \mathrm{C}$. Rise in temperature can be observed in the class agriculture land and open land area where the soils are open and emitting high heat radiations (Figure 5, Table $3 \& 4$ ). It is observed from the study the area under the range of $27-30^{\circ} \mathrm{C}$ cover the maximum area that is around $107 \mathrm{~km}^{2}$. Other class in 2000 , which covers the maximum area of $65 \mathrm{~km}^{2}$ that ranges between $25-27^{\circ} \mathrm{C}$ and greater than $35^{\circ} \mathrm{C}$ in temperature covers only $0.05 \mathrm{~km}^{2}$ of the area (Table 3 ).

In 2016, the minimum and maximum land surface temperature observed in the study was $26^{\circ} \mathrm{C}$ and $37^{\circ} \mathrm{C}$ respectively with the mean of $31^{\circ} \mathrm{C}$. The result shown that there is straight increase of $2^{\circ} \mathrm{C}$ maximum temperature and $1{ }^{\circ} \mathrm{C}$ minimum temperature in last 16 years 
Shastri S., Singh P., Verma P., Rai P.K, Singh A.P.: Land cover change dynamics and their impacts on thermal environment of Dadri Block, Gautam Budh Nagar, India

(Figure 6, Table $3 \& 4$ ). If we consider the vegetation distribution for this year it is sparely distributed and region has more agricultural patches than vegetation covers. The land surface temperature (LST) distribution for 2016, the maximum surface area covere by temperature ranging $33-35^{\circ} \mathrm{C}$ that is $96 \mathrm{~km}^{2}$ areas, and the area covered by the class which is greater than $35^{\circ} \mathrm{C}$ covers $64 \mathrm{~km}^{2}$ of the total area, whereas lower temperatures exist only in patches around the vegetation cover.

Fig. 5: LST of year 2000

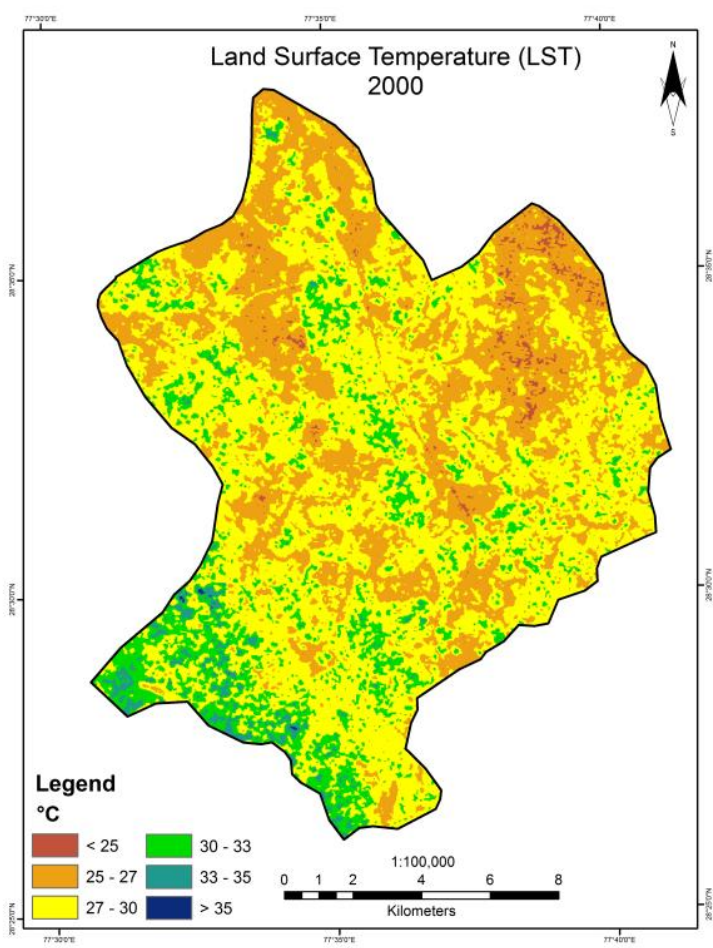

Fig. 6: LST of year 2016

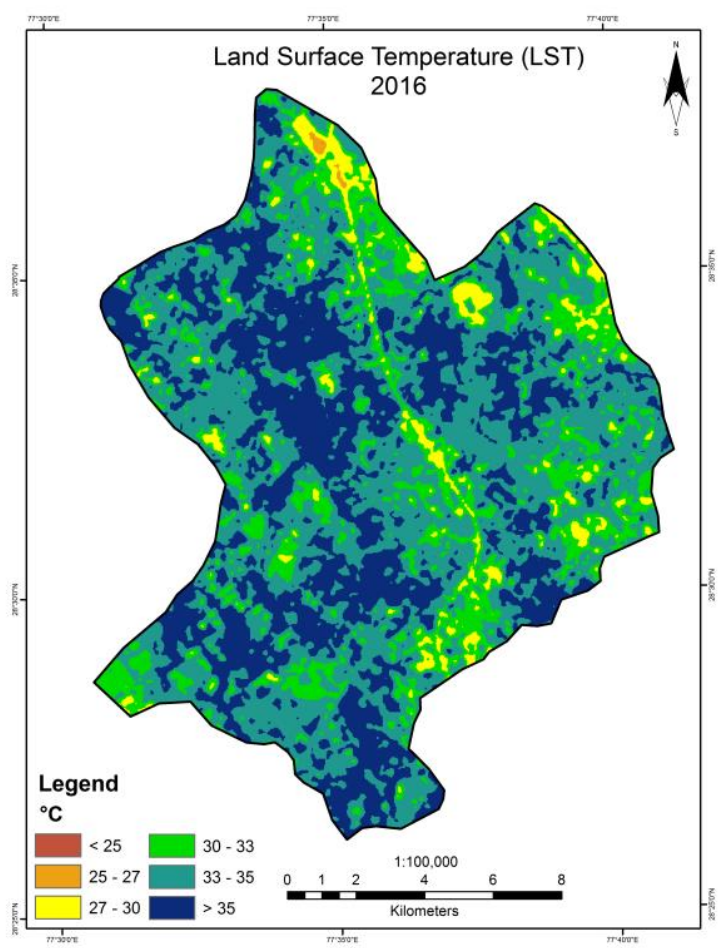

Table 3: Land surface temperature with minimum, maximum and mean value

\begin{tabular}{|c|c|c|c|}
\hline \multirow{2}{*}{ Temperature $\left({ }^{\circ} \mathrm{C}\right)$} & \multicolumn{2}{|c|}{ Years } & \multirow[b]{2}{*}{ Change $\left({ }^{\circ} \mathrm{C}\right)$} \\
\hline & 2000 & 2016 & \\
\hline Min & 24.64 & 25.93 & 1.29 \\
\hline Max & 35.13 & 37.03 & 1.90 \\
\hline Mean & 29.88 & 31.48 & 1.60 \\
\hline
\end{tabular}


Table 4: Area Distribution of Land Surface Temperature

\begin{tabular}{|c|c|c|}
\hline Class (LST) & $\mathbf{2 0 0 0}$ (sq. $\mathbf{~ k m . )}$ & $\mathbf{2 0 1 6}$ (sq. $\mathbf{~ k m}$. $)$ \\
\hline$<\mathbf{2 5}$ & 1.84 & - \\
\hline $\mathbf{2 5 - 2 7}$ & 64.9 & 0.3 \\
\hline $\mathbf{2 7 - 3 0}$ & 107.5 & 8.4 \\
\hline $\mathbf{3 0 - 3 3}$ & 24.9 & 34.6 \\
\hline $\mathbf{3 3 - 3 5}$ & 3.6 & 95.7 \\
\hline$>\mathbf{3 5}$ & 0.05 & 63.8 \\
\hline
\end{tabular}

\section{DISCUSSION}

In general, urbanisation is the main driving force of LULC changes which consequently increases the LST. This study further confirms that the change in surface temperature are mostly a consequence of LULC change due to rapid population growth which is also evidenced by our change analysis using satellite based land cover classification. It may be mentioned that the change in NDVI pattern also coincides with the LULC change pattern (Jalan \& Shamrma, 2014). This study support the notion that the LULC change is associated with the changes to green cover and is related to vegetation or agriculture. The significant indicators modulating LST are surface level soil moisture content and vegetation cover in the area (Kalnay \& Cai, 2003). Changes to these can modify the soil thermal properties and evapotranspiration (Sharma et.al., 2017). It is known that rise in the soil moisture leads to rise in the soil thermal capacity, conductivity and inertia thereby slowing the rise in the LST. In addition, surface heat fluxes such as the Latent Heat Flux (LHF) and Sensible Heat Flux (SHF) get modified with changes to land use. LHF (SHF) increases (decreases) with increasing vegetation leading to a decrease in LST (Weng et. al., 2004; Su et. al., 2010; Zong-Ci et.al., 2013; Pielke et.al., 2010; Jiang et.al., 2015; Jain et. al, 2017; Pandey et. al., 2017; Sharma et.al., 2017; He et.al., 2017). The important cause for the retrieved higher LST values than the actual values is the effect of the surface roughness which is not taken into consideration when retrieving the LST value (Pal \& Ziaul, 2017). Study says that the LST is mainly influenced by the land surface structure, water content and chemical composition (Siu \& Hart, 2013). According to Bokaie et al. (2016), who confirmed that, in order to improve the outcomes of LST, the temperature of every part of the vegetation-ground system must be taken into account. Additionally, the different canopy structures may also react as a factor in affecting the surface temperature. The results show that the non-vegetated areas have a positive influence on the increasing temperatures in urban areas. These observations are consistent with Zhao et al. (2011) and Connors et al. (2013) who analysed that non-vegetated areas have an impact in increasing the LST of urban area.

\section{Relationship between Land Use with LST}

The study is based on the thermal signature of the each class of land use that is essential to understand the relationship between land surface temperature and land cover (Weng et al., 2004). Hence, a comparison between LULC and LST has been done by comparing selected sampling points of the LULC with LST values. The average temperature of each land use class was calculated by averaging the values of pixel of a particular land use class (Singh et.al., 2017). The result indicates that highest LST value found in built-up, agriculture and 
Shastri S., Singh P., Verma P., Rai P.K, Singh A.P.: Land cover change dynamics and their impacts on thermal environment of Dadri Block, Gautam Budh Nagar, India

open land class, while the lowest was observed in the vegetation cover and water bodies. This is due to the heat emission from open and complex built-up. In other words, built-up land has a tendency to retain the heat longer than other land cover classes such as barren land on the outskirts that does not retain heat for long time.

\section{CONCLUSION}

The work based on assessment of multi temporal satellite images to for land use/ land cover mapping and its impact and relation to increasing land surface temperature (LST) of the Dadri block of Gautam Budh Nagar, Uttar Pradesh, India has clearly shown that the urbanization and land use change practices are the major drivers for increasing land surface temperature and local environment. The built-up, agricultural land, vegetation, open land and water bodies are the major classes and classified images shown drastic changes in built-up area around $9 \%$, whereas other classes such as agricultural, vegetation and open land also decreased by $3 \%, 1.3 \%$ and $2 \%$ respectively. The study shows that the land use/land cover and LST have a strong relationship. In addition, the study found that the vegetation area and water bodies have a negative relationship with the land surface temperature. The LST was highly influenced by the built-up, very sensitive to vegetation. Higher LST observed in areas with less vegetated and high built-up and vice versa. The present work shown that that earth observation datasets extracted from satellite imageries provides accurate and comprehensive information on effects of Land use, Vegetation Cover and Urbanisation on the environmental sustainability of urban and suburban environment. Remote Sensing and associated technologies like GIS offer tools which can accurately map and estimate changes in various factors impacting the environmental vulnerability of an area. Use of such tools is an inescapable requirement for modern day management of both urban and non-urban areas.

\section{REFERENCES}

Alipour, T., Sarajian, M.R. and Esmaeily, A. (2003). Land Surface Temperature Estimation from Thermal Band of Landsat Sensor, Case Study: Alashtar City. The International Achieves of the Photogrammetry, Remote Sensing and Spatial Information Sciences, 38.

Amiri, R., Weng, Q., Alimohammadi, A., AlavipanahS. K., (2009). Spatial-temporal dynamics of land surface temperature in relation to fractional vegetation cover and land use/cover in the Tabriz urban area, Iran. Remote Sensing of Environment, 113, 2606-2617.

Basara, J.B., Basara, H.G., Illston, B.G., Crawford, K.C. (2010). The impact of the urban heat islands during an intense heat wave in Oklahoma city. Adv. Meterol., doi:10.1155/2010/230365.

Bokaie, M., Zarkesh, M.K., Arasteh, P.D., \& Hosseini, A. (2016).Assessment of urban heat island based on the relationship between land surface temperature and land use/land cover in Tehran. Sustainable Cities and Society, 23, 94-104. doi:10.1016/j.scs.2016.03.009

Connors, J.P., Christopher, S.G., Winston, T.L.C., (2013). Landscape configuration and urban heat island effects: assessing the relationship between landscape characteristics and land surface temperature in Phoenix, Arizona. Landscape Ecology, 28: 271-283.

Chen, X.L., Zhao, H.M., Li, P.X. \& Yin, Z.Y. (2006). Remote sensing image-based analysis of the relationship between urban heat island and land use/cover changes. Remote Sensing of 
Environment, 104(2), 133-146.

Cristóbal, J., Jiménez-Muñoz, J., Sobrino, J., Ninyerola, M., \& Pons, X. (2009). Improvements in land surface temperature retrieval from the Landsat series thermal band using water vapor and air temperature. Journal of Geophysical Research: Atmospheres, 114(D8).

Chaudhuri, A. S., Singh, P., \& Rai, S. C. (2017). Assessment of impervious surface growth in urban environment through remote sensing estimates. Environmental Earth Sciences, 76, 541-553. https://doi.org/10.1007/s1266 5-017-6877-1.

Chaudhuri, A. S., Singh, P., and Rai, S. C. (2018). Modelling LULC change dynamics and its impact on environment and water security: geospatial technology based assessment.\| Eco. Env. \& Cons 24, 300-306

Fatemi, M., Narangifard, M. (2019). Monitoring LULC changes and its impact on the LST and NDVI in District 1 of Shiraz City. Arab J Geosci., 12, 127. https://doi.org/10.1007/s12517-019-4259-6

Hou, G. L., Zhang, H. Y., Wang, Y. Q., Qiao, Z. H. \& Zhang, Z. X. (2010). Retrieval and Spatial Distribution of Land Surface Temperature in the Middle Part of Jilin Province Based on MODIS Data. Scientia Geographica Sinica 30, 421-427.

Harlan, S.L., Brazel, A.J., Prashad, L., Stefanov, W.L., Larsen, L. (2006) Neighborhood microclimates and vulnerability to heat stress. Soc. Sci. Med., 63, 2847-2863.

He, Y., Lee, E. \& Warner, T. A. (2017). A time series of annual land use and land cover maps of China from 1982 to 2013 generated using AVHRR GIMMS NDVI3g data. Remote Sens. Environ. 199, 201-217.

Jain, M., Dimri, A. \& Niyogi, D.(2017). Land-Air Interactions over Urban-Rural Transects Using Satellite Observations: Analysis over Delhi, India from 1991-2016. Remote Sens. 9, $1-14$.

Jiang, Y., Fu, P. \& Weng, Q. (2015). Assessing the impacts of urbanization-associated land use/cover change on land surface temperature and surface moisture: A case study in the midwestern united states. Remote Sens. 7, 4880-4898.

Jalan, S. \& Sharma, K. (2014). Spatio-temporal assessment of land use/land cover dynamics and urban heat island of Jaipur city using satellite data. In International Archives of the Photogrammetry, Remote Sensing and Spatial Information Sciences - ISPRS Archives XL-8, 767-772.

Kalnay, E. \& Cai, M. (2003). Impact of urbanization and land-use change on climate. Nature 423, 528-531.

Kikon, N., Singh, P., Singh, S.K, Vyas, A. (2016). Assessment of urban heat islands (UHI) of Noida City, India using multi-temporal satellite data. Sustainable Cities and Society 22 (2016) pp. 19-28.

Lafortezza, R., Carrus, G., Sanesi, G., Davies, C. (2009). Benefits and wellbeing perceived by people visiting green spaces in periods of heat stress. Urban For. Urban Green , 8, 97108.

Li, S., Zhao, Z., Miaomiao, X., \& Wang, Y. (2010). Investigating spatial non-stationary and scale-dependent relationships between urban surface temperature and environmental factors using geographically weighted regression. Environmental Modelling \& Software, 25(12), 1789-1800.

Li, Y., Zhanga, H., Kainz, W., (2012). Monitoring patterns of urban heat islands of the 
Shastri S., Singh P., Verma P., Rai P.K, Singh A.P.: Land cover change dynamics and their impacts on thermal environment of Dadri Block, Gautam Budh Nagar, India

fast-growing Shanghai metropolis, China: Using time-series ofLandsat TM/ETM+ data. International Journal of Applied Earth Observation and Geoinformation 19, pp127-138

Mishra, V. and Rai, P.K., (2016). A Remote sensing Aided Multi-Layer Perceptron-Marcove Chain Analysis for Land Use and Land Cover Change Prediction in Patna district (Bihar), India, Arabian Journal of Geosciences, Vol 9 (1). Pp.1-18. DOI: 10.1007/s12517-015-2138-3.

Mishra, V.N., Prasad, R., Kumar, P. et al. (2019). Assessment of Spatio-Temporal Changes in Land Use/Land Cover Over a Decade (2000-2014) Using Earth Observation Datasets: A Case Study of Varanasi District, India. Iran J Sci Technol Trans Civ Eng 43, 383-401. https://doi.org/10.1007/s40996-018-0172-6

Owen, T. W., Carlson, T. N. \& Gillies, R. R. (1998). An assessment of satellite remotely-sensed land covers parameters in quantitatively describing the climatic effect of urbanization. International Journal of Remote Sensing, 19:9, pp.1663-1681.

Pandey, S. K., Vinoj, V., Landu, K. \& Babu, S. S. (2017). Declining pre-monsoon dust loading over South Asia: Signature of a changing regional climate. Sci. Rep. 7, 1-10.

Pielke, R. A. et al. (2011). Land use/land cover changes and climate: Modeling analysis and observational evidence. Wiley Interdiscip. Rev. Clim. Chang. 2, 828-850.

Pal, S., \& Ziaul, S. (2017). Detection of land use and land cover change and land surface temperature in English Bazar urban centre. The Egyptian Journal of Remote Sensing and Space Science, 20(1), 125-145. doi:10.1016/j.ejrs.2016.11.003.

Quattrochi, D.A., Luvall, J.C. (1999). Thermal infrared remote sensing for analysis of landscape ecological processes: Methods and applications. Landscape Ecology 14 (6), 577_598

Siu, L.W., \& Hart, M.A. (2013). Quantifying urban heat island intensity in Hong Kong SAR, China. Environmental Monitoring and Assessment, 185(5), 4383-4398. doi:10.1007/s10661-012-2876-6.

Saud, S., Fahad, S., Yajun, C., Ihsan, M.Z., Hammad, H.M., Nasim, W., Jr A, Arif, M., Alharby, H. (2017). Effects of nitrogen supply on water stress and recovery mechanisms in Kentucky bluegrass plants. Front Plant Sci 8:983. https://doi.org/10.3389/fpls.2017.00983

Shastri, H., Barik, B., Ghosh, S., Venkataraman, C. \& Sadavarte, P. (2017). Flip flop of Day-night and Summer-Winter Surface Urban Heat Island Intensity in India. Sci. Rep. 7, 18 .

Su, W., Gu, C. \& Yang, G. (2010). Assessing the Impact of Land Use/Land Cover on Urban Heat Island Pattern in Nanjing City, China. J. Urban Plan. Dev. 136, 365-372.

Singh, S. and Rai, P.K. (2017). Application of Earth Observation Data for Estimation of Changes in Land Trajectories in Varanasi District, India, Journal of Landscape Ecology. DOI: 10.1515/jlecol-2017-0017.

Singh, P, Thakur, JK, Kumar, S, Singh, UC (2012). Assessment of Land Use/Land Cover Using Geospatial Techniques in a Semi-arid Region of Madhya Pradesh, India. In: Thakur Singh, Prasad Gossel (eds) Geospatial techniques for managing environmental resources. Springer, Heidelberg, pp 152-163

Singh, P., Noyingbeni, K., and Verma, P. (2017). Impact of Land Use Change and Urbanization on Urban Heat Island in Lucknow City, Central India. A Remote Sensing Based Estimate. Sustainable Cities and Society, 32, 100-114. https://doi.org/10.1016/j.scs.2017.02.018. 
Stafoggia, M., Schwartz, J., Forastiere, F., Perucci, C.A. (2008). Does temperature modify the association between air pollution and mortality? A multicity case-cross over analysis in Italy. Am. J. Epidemiol., 167, 1476-1485.

Sharma, A. et al. (2017). Urban meteorological modeling using WRF: a sensitivity study. Int. J. Climatol. 37, 1885-1900.

Verma, P, Singh, P. and Srivastava, S. K.. (2019). Impact of Land Use Change Dynamics on Sustainability of Groundwater Resources Using Earth Observation Data. Environment, Development and Sustainability. https://doi.org/10.1007/s10668-019-00420-6.

Weng, Q., Lu, D., Schubring, J. (2004). Estimation of Land Surface Temperature-Vegetation abundance relationship for urban heat island studies. Remote Sens. Environ., 89, 467-483.

Woodcock, C. E. and Strahler, A. H., (1987). "The factor of scale in remote sensing," Remote Sens. Environ., vol. 21, pp. 311-22.

Weng, Q., Lu, D. Schubring, J., (2004). Estimation of land surface temperaturevegetation abundance relationship for urban heat island studies. Remote sensing of Environment 89 (4): 467_483.

Weng, Q. (2009). Thermal infrared remote sensing for urban climate and environmental studies: Methods, applications, and trends, ISPRS Journal of Photogrammetry and Remote Sensing 64,pp335_344.

Zong-Ci, Z., Yong, L. \& Jian-Bin, H. (2013). Are There Impacts of Urban Heat Island on Future Climate Change? Adv. Clim. Chang. Res. 4, 133-136.

Zhang, Y., Odeh, I. and Han, C., (2009). "Bi-temporal characterization of land surface temperature in relation to impervious surface area, NDVI and NDBI, using a sub-pixel image analysis," Int. J. Appl. Earth Observation Geoinform., vol. 11, pp. 256-264.

Zhao, C., Fu, G., Liu, X., Fu, F., (2011) Urban planning indicators, morphology and climate indicators: a case study for a north- south transect of Beijing, China. Bul. Environ., 46: 1174-1183 